\title{
Synthesis of Biological Active Esters of the Isovaleric Acid by Isobutylene Hydroalkoxycarbonylation
}

\author{
Suerbaev KA*, Zhaksylykova GZ, Appazov NO \\ Al-Faraby Kazakh National University, Almaty, Republic of Kazakhstan
}

\begin{abstract}
Hydroalkoxycarbonylation of 2-methylpropene with carbon monoxide and alcohols under condition of homogeneous catalysis with transition metal complexes allows facile one-step synthesis of practically useful isovaleric acid esters. Many of them exhibit biological activity and are constituents of drugs (Validolum, Corvalolum, etc.) or valuable intermediate products in drug synthesis. Biological active isovaleric acid esters (1-menthylisovalerate ethylisovalerate, cyclohexylisovalerate, benzylisovalerate, $\alpha$-monoglyceryde of isovaleric acid) were prepared by isobutylene hydroalkoxycarbonylation. New efficient technologies for preparation of drugs (Validolum, Ethyl ester of $\alpha$-bromisovaleric acid and Corvalolum) are based on the isovaleric acid esters were worked out.
\end{abstract}

Keywords: Synthesis; Isovaleric acid; Esters; Drugs; Isobutylene; Hydroalkoxycarbonylation; Technologies

\section{Introduction}

Isobutylene as an accessible and inexpensive feedstock is of interest for synthesis of many practically useful compounds. Isobutylene carbonylation with carbon monoxide and alcohols under conditions of homogeneous catalysis with transition metal complexes allows facile one-step synthesis of practically useful isovaleric acid esters [1-5]. Many of them have biological activity and are components of pharmaceuticals (Validolum, Corvalolum, etc) or valuable intermediates for their synthesis. Some isovalerate esters possess a characteristic odor and are used as fragrance compounds in the manufacture of perfumes, cosmetics and food essences [6].

We applied hydroalkoxycarbonylation of isobutylene with carbon monoxide and mono(poly)hydric alcohols in the presence of catalytic systems based on the phosphinpalladium complexes $\left(\mathrm{Pd}\left(\mathrm{PPh}_{3}\right)_{4}-\mathrm{PPh}_{3}-\right.$ $\mathrm{TsOH}$ and $\mathrm{Pd}(\mathrm{Acac}) 2-\mathrm{PPh} 3-\mathrm{TsOH})$ to prepare of biological active isovaleric acid esters: 1-menthylisovalerate (possesses spasmolytic properties; it used as main active component of the spasmolytic medicine Validolum), ethylisovalerate (possesses aromatic (fruit) odor; intermediate product for obtaining sedative and spasmolytic medicines Ethyl ester of a-bromisovaleric acid and Corvalolum), cyclohexylisovalerate (bactericide activity (against Staphylococcus aureus, Escherichia coli, Pseudomonas aeruginosa); antifungal activity (against Candida albicans)), benzylisovalerate (bactericide activity (against Escherichia coli, Staphylococcus aureus)) and $\alpha$-monoglyceryde of isovaleric acid (bactericide activity (against Escherichia coli, Pseudomonas aeruginosa); antifungal activity (against Candida albicans)).

New efficient technologies for preparation of drugs are based on isovaleric acid esters - Validolum, Ethyl Ester of a-bromisovaleric acid (EEBIA) and Corvalolum - were worked out. Validolum - is a spasmolytic (sedative) medicine. It has a sedative effect on the nervous system and a moderate reflex vaso-dilating effect. EEBIA possesses sedative and spasmolytic properties. It is included in Corvalolum composition and may be used for producing other medicines. Corvalolum is a combined medicine and consists of EEBIA, phenobarbital, sodium hydroxide, peppermint oil, ethyl alcohol and water. Corvalolum possesses anetic and spasmolytic properties.

Due to the more advanced technology of production the Medicines will have better qualitative characteristics. The cost of production of the Medicines with the use of new technologies is 2-3 times lower as compared to the medicines produced by existing at the present traditional technologies.

\section{Experimental}

The complexes $\mathrm{Pd}\left(\mathrm{PPh}_{3}\right)_{4}$ and $\mathrm{Pd}(\mathrm{Acac})_{2}$ was obtained according to the known procedures [7]. $\mathrm{p}$-Toluenesulfonic acid was recrystallized from $96 \%$ ethanol and dried until the composition $\mathrm{TsOH}^{\star} \mathrm{H}_{2} \mathrm{O}$. Triphenylphosphine was recrystallized from an ether-ethanol mixture to a constant melting point. Absolute ethanol, isobutylene of $99,5 \%$ purity, carbon monoxide of $99,8 \%$ purity, 1-menthol of $99,7 \%$ purity, cyclohexanol of $99,5 \%$ purity, benzyl alcohol of $99,2 \%$ purity and glycerin of $99,5 \%$ purity were used. The experiments were carried out in the solvent-free mode in a laboratory stainless steel autoclave unit. The determination of the purity and the analysis of the products were carried out by means of a GLC technique, thin-layer chromatography, IR-spectroscopy and ${ }^{1} \mathrm{H}$ NMR techniques. Gas chromatography was performed on a Hewlett-Packard 3890-II-Plus chromatograph with a flameionization detector; HP-Innowax cross-linked PEG capillary column $\left(30000^{*} 0,25 \mathrm{~mm}\right)$, film thickness $0,25 \mu \mathrm{m}$. Injector temperature $200^{\circ} \mathrm{C}$, detector temperature $200^{\circ} \mathrm{C}$, carrier gas nitrogen $(25 \mathrm{ml} /$ $\mathrm{min})$. The oven temperature was programmed from 75 to $175^{\circ} \mathrm{C}$ at a rate of $10^{\circ} \mathrm{C} / \mathrm{min}$. The ${ }^{1} \mathrm{H}$ NMR spectra were measured on a Varian Mercury-300 instrument (300 MHz) against internal TMS.

\section{L-Menthyl Isovalerate}

The $100 \mathrm{ml}$ autoclave equipped with a stirrer and a carbon

*Corresponding author: Suerbaev KA, Al-Faraby Kazakh National University, Almaty, Republic of Kazakhstan, Tel: 727-292-57-17; E-mail: khsuerbaev@mail.ru

Received November 15, 2013; Accepted December 30, 2013; Published January 07, 2013

Citation: Suerbaev KA, Zhaksylykova GZ, Appazov NO (2013) Synthesis of Biological Active Esters of the Isovaleric Acid by Isobutylene Hydroalkoxycarbonylation. J Pet Environ Biotechnol 4: 164. doi:10.4172/21577463.1000164

Copyright: (C) 2013 Suerbaev KA, et al. This is an open-access article distributed under the terms of the Creative Commons Attribution License, which permits unrestricted use, distribution, and reproduction in any medium, provided the original author and source are credited. 
monoxide and isobutylene feeding device was charged with $0,133 \mathrm{~g}$ $\left(1,15^{\star} 10^{-4} \mathrm{~mol}\right)$ of $\mathrm{Pd}\left(\mathrm{PPh}_{3}\right), 0,263 \mathrm{~g}\left(1,38^{\star} 10^{-3} \mathrm{~mol}\right)$ of $\mathrm{TsOH}$, and $7,854 \mathrm{~g}\left(5,02^{\star} 10^{-2} \mathrm{~mol}\right)$ of 1 -menthol. The autoclave was sealed, purged with CO to remove air, and filled with $\mathrm{CO}$ to a pressure of 1,0-1,1 MPa. Then $3,562 \mathrm{~g}\left(6,35^{\star} 10^{-2} \mathrm{~mol}\right)$ of isobutylene was introduced and stirring and heating were switched on. The carbon monoxide pressure was brought to $2,0 \mathrm{MPa}$, the temperature was elevated within $1 \mathrm{~h}$ to $100^{\circ} \mathrm{C}$, and the reaction mixture was agitated under these conditions for $4 \mathrm{~h}$. On completion, the autoclave was cooled to room temperature and the reaction mixture was fractionated in a vacuum. $3,58 \mathrm{~g}(45,6 \%$ of the initial quantity) of unreacted l-menthol and 6,24 g (51,6\%) (or 94,9\% on converted l-menthol) of l-menthyl isovalerate were obtained. Bp $123^{\circ} \mathrm{C} / 6 \mathrm{~mm} \mathrm{Hg}, \mathrm{n}_{\mathrm{D}}{ }^{20} 1,4480$.

\section{Isovaleric acid $\alpha$-monoglyceride}

A steel autoclave of $100 \mathrm{ml}$ capacity was charged with $0,035 \mathrm{~g}$ $\left(1,15^{\star} 10^{-4} \mathrm{~mol}\right)$ of Pd (Acac) $)_{2}, 0,212 \mathrm{~g}\left(8,085^{\star} 10^{-4} \mathrm{~mol}\right)$ of $\mathrm{PPh}_{3}, 0,263$ $\mathrm{g}\left(1,386^{\star} 10^{-3} \mathrm{~mol}\right)$ of $\mathrm{TsOH}$, and $5,975 \mathrm{~g}\left(6,35^{\star} 10^{-2} \mathrm{~mol}\right)$ of glycerin. The autoclave was sealed, purged twice with $\mathrm{CO}$ to remove air from the system, and then filled with CO to a pressure of 1,0-1,1 MPa. After that $7,125 \mathrm{~g}\left(12,7^{\star} 10^{-2} \mathrm{~mol}\right)$ of isobutylene was introduced into the autoclave, and the carbon monoxide pressure was increased to 2,0 $\mathrm{MPa}$. Stirring and heating were switched on. The reaction mixture was stirred within $4 \mathrm{~h}$ at a temperature of $100^{\circ} \mathrm{C}$ and a pressure of $2,0 \mathrm{MPa}$. Then the autoclave was allowed to cool down to a room temperature and left for a night. The next day, after the pressure was released to atmospheric, the reaction mixture was fractionated in a vacuum. The desired products were separated from the obtained mixture of products with unreacted glycerin by means of column adsorption chromatography on silica gel $(0,005-0,04 \mathrm{~mm})$. Chloroform and chloroform: methanol blend ( $9: 1$ by volume) were used as eluents. $1,81 \mathrm{~g}(30,8 \%$ of the initial quantity) of unreacted glycerin, $0,91 \mathrm{~g}(16,2 \%)$ (or $23,2 \%$ on converted glicerin) of isovaleric acid $\alpha$-monoglyceride and $1,08(13,1 \%$ ) (or $18,7 \%$ on converted glicerine) of isovaleric acid $\alpha, \alpha^{\prime}$-diglyceride were obtained. Isovaleric acid $\alpha$-monoglyceride, $\mathrm{Bp} 187^{\circ} \mathrm{C} / 30 \mathrm{~mm} \mathrm{Hg}, \mathrm{n}_{\mathrm{D}}{ }^{20} 1,4440$. Isovaleric acid $\alpha, \alpha^{\prime}$-diglyceride, $\mathrm{Bp} 198^{\circ} \mathrm{C} / 24 \mathrm{~mm} \mathrm{Hg}, \mathrm{n}_{\mathrm{D}}{ }^{20} 1,4390$.

\section{Results and Discussion}

Hydroalkoxycarbonylation reaction of isobutulene with carbon monoxide and monohydric alcohols (ethanol, cyclohexanol, l-menthol, benzyl alcohol) in the presence $\mathrm{Pd}\left(\mathrm{PPh}_{3}\right)_{4}-\mathrm{PPh}_{3}-\mathrm{TsOH}$ system carried out at optimal conditions of isobutylene hydromenthoxycarbonylation [8]: temperature $100^{\circ} \mathrm{C}$; $\mathrm{CO}$ pressure $2,0 \mathrm{MPa}$; reaction time $4 \mathrm{~h}$; reactants and catalyst components ratio [alcohol]:[isobutylene]:[ $\operatorname{Pd}(\mathrm{P}$ $\left.\left.\mathrm{Ph}_{3}\right)_{4}\right]:\left[\mathrm{PPh}_{3}\right]:[\mathrm{TsoH}]=435: 550: 1: 3: 12$. The yields of the products were $71-95 \%$ (on converted alcohols).

Synthesis of isovaleric acid $\alpha$-monoglyceride carried out at optimal conditions of hydroalkoxycarbonylation of isobutylene with carbon monoxide and glycerin in the presence of $\mathrm{Pd}(\mathrm{Acac})_{2}-\mathrm{PPh}_{3}-\mathrm{TsOH}$ system [9]: temperature $100^{\circ} \mathrm{C}$; $\mathrm{CO}$ pressure $2,0 \mathrm{MPa}$; reaction time $3 \mathrm{~h}$; reactants and catalyst components ratio [glycerin]:[isobutylene]:[ $\mathrm{Pd}(\mathrm{A}$ (ac) $\left.)_{2}\right]:\left[\mathrm{PPh}_{3}\right]:[$ TsoH $]=550: 1100: 1: 7: 12$. The yield of the isovaleric acid a-monoglyceride was $18,7 \%$ (on converted glicerin).

The selectivity in linear reaction products was $100 \%$. Such a high regioselectivity is apparently provided both by the structure of the starting alkene (isobutylene) and by the reaction mechanism. The most probable is a hydride mechanism. Evidence for this proposal comes

$$
\left(\mathrm{CH}_{3}\right)_{2} \mathrm{C}=\mathrm{CH}_{2}+\mathrm{CO}+\mathrm{ROH} \stackrel{[\mathrm{Pd}]-\mathrm{PPh}_{3}-\mathrm{TsOH}}{\longrightarrow}\left(\mathrm{CH}_{3}\right)_{2} \mathrm{CHCH}_{2} \mathrm{C}(\mathrm{O}) \mathrm{OR}
$$

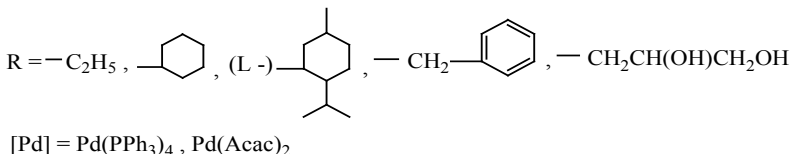

from the observation of an exceptionally strong effect of the $\mathrm{TsOH}$ addition, which being a proton donor, facilitates formation of the primary active hydride complexes of the catalytic cycle.

L-Menthylisovalerate is a main active ingredient of the drug Validolum. Validolum has a sedative effect on the nervous system and a moderate reflex vaso-dilating effect. It is used at light attacks of stenokardia, neurosis, hysteria. It is also used as anantienetic at sea air sickness.

The existing industrial production of Validolum is based on the two stage scheme of the synthesis of 1-menthylisovalerate: 1) oxidation reaction of isoamil alcohol to isovaleric acid; 2 ) esterification reaction of isovaleric acid by l-menthol. Such a technology of obtaining 1-menthylisovalerate is characterized by low technical-economic (duration of the esterification process is $48 \mathrm{~h}$., yield of the target product no more than $75 \%$ ) and low ecological characteristics (large amounts of waste waters at the stages of neutralization and washing) and low quality of products because of the presence of impurities. Validolum obtained by traditional technology contains 11 admixtures, the content of which reaches $8 \%$.

The new technology developed by us makes possible to make the synthesis of 1-menthylisovalerate in one stage by reaction of hydromenthoxycarbonylation of isobutylene by carbon monoxide and 1 -menthol in the presence of metalcomplex catalyst. The use of the more available raw materials and also the high effectiveness of the technology (duration of the process is $5 \mathrm{~h}$., yield of the target product 95\%) makes this process of obtaining l-menthylisovalerate highly profitable. The product obtained with the new technology has higher quality and contains only 3-4 admixtures, the contents of all of which is not higher than $1-1,5 \%$.

EEBIA possesses sedative and spasmolytic properties and in larger doses provides light soporific action. It is included in composition of the drug Corvalolum and may be used for producing other medicines. Corvalolium possesses anetic and spasmolytic properties. It is used for neurosis with increased irritability, for soft spasms of coronary vessels, tachycardia, anhypnosis, early stages of hypertension and bowel spasms.

The existing technology of EEBIA production is based on the four stage scheme of the synthesis. The first stage is obtaining of isovaleric acid by oxidation of isoamyl alcohol. Then follows the two staged bromination of isovaleric acid with bromine in the presence of $\mathrm{PCl}_{3}$. The obtained $a$-bromisovaleric acid is transferred into chloranhydride, which is subjected to esterification with ethanol. This method of EEBIA obtaining is characterized with complexity and is highly labor consuming process, has low technical, economic and ecological characteristics (use of expensive and rare raw materials, use and formation of aggressive starting products and secondary by-products: $\left.\mathrm{PCl}_{3}, \mathrm{HCl}, \mathrm{H}_{3} \mathrm{PO}_{4}\right)$ and the low quality of the product due to the admixtures.

$$
\begin{aligned}
& \text { 1. } \mathrm{CH}_{3}-\mathrm{CH}_{3}-\mathrm{CH}_{2}-\mathrm{CH}_{2} \mathrm{OH} \stackrel{[\mathrm{O}]}{\longrightarrow} \mathrm{CH}_{3} \underset{\mathrm{CH}_{3}}{\mathrm{CH}} \mathrm{OH}_{2} \stackrel{\mathrm{O}}{\mathrm{C}} \mathrm{OH}
\end{aligned}
$$

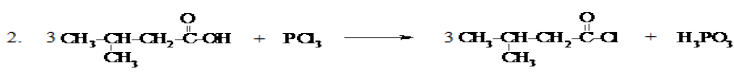

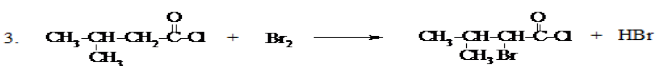

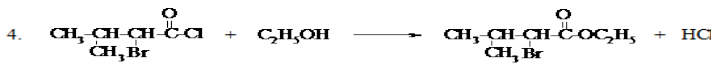


Citation: Suerbaev KA, Zhaksylykova GZ, Appazov NO (2013) Synthesis of Biological Active Esters of the Isovaleric Acid by Isobutylene Hydroalkoxycarbonylation. J Pet Environ Biotechnol 4: 164. doi:10.4172/2157-7463.1000164

The proposed by us new technology of obtaining EEBIA (and Corvalolum production on its basis) is based on the new effective method of obtaining EEBIA from isobutylene, carbon monoxide, ethanol and bromine. The synthesis of ethylisovalerate is carried out by hydroethoxycarbonilation reaction of isobutylene by carbon monoxide and ethanol in the presence of metalcomplex catalyst. On the second stage the product (EEBIA) is synthesized by bromination of ethylisovalerate in the presence of the red phosphor. Quality of EEBIA obtained by the new technology is higher (contains less admixtures), the production costs are 2-3 times lower than the production costs of the existing four stage method of obtaining EEBIA.

$$
\begin{aligned}
& \text { 1. } \mathrm{CH}_{3}-\mathrm{C}=\mathrm{CH}_{2}+\mathrm{CO}+\mathrm{C}_{2} \mathrm{H}_{5} \mathrm{OH} \longrightarrow \mathrm{CH}_{3}-\mathrm{CH}-\mathrm{CH}_{2}-\stackrel{\mathrm{O}}{\mathrm{C}}-\mathrm{OC}_{2} \mathrm{H}_{5} \\
& \mathrm{CH}_{3}
\end{aligned}
$$

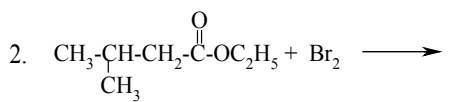

$$
\begin{aligned}
& \underset{\substack{\mathrm{C} \\
\mathrm{CH}}, \mathrm{Br}}{\stackrel{\mathrm{B}}{\mathrm{C}}-\mathrm{C}-\mathrm{OC}_{2} \mathrm{H}_{5}+\mathrm{HBr}}
\end{aligned}
$$

a-Monoglyceride of isovaleric acid was synthesized by carbonylation of isobutylene with carbon monoxide in the presence of glycerin and the catalyst system $\mathrm{Pd}(\mathrm{Acac})_{2}-\mathrm{PPh}_{3}-\mathrm{TsOH}$. According to available data, the secondary hydroxyl group of glycerin reacts more slowly than a primary one. At ratios of [isobutylene]:[glycerin] $=1: 1$ and 2:1, monoand diglycerides are formed, and mono-, di- and triglycerides are formed when the ratio is 1:3. The maximum total yield of glycerides $(23,3 \%)$ was obtained at a ratio of [isobutylene]:[glycerin] $=2: 1$; the yields of monoglyceride and diglyceride make up 19,1 and $4,2 \%$, respectively, in this case. The yields of mono- and diglycerides at [isobutylene]: [glycerin] $=1: 1$ are 9,3 and $1,1 \%$, respectively. At a ratio of [isobutylene]:[glycerin] $=3: 1$, mono-, di-, and triglycerides were obtained with yields of $14.7,3,0$ and $0,4 \%$, respectively.

Note that, in contrast to the known processes for the manufacture of glycerides of fatty acids by the direct esterification of the acids with glycerin and by transesterification of methyl (or ethyl) esters of fatty acids with glycerin when a mixture of $\alpha$ - and $\beta$-isomers of monoglycerides is formed, the formation of the $\alpha$-isomer alone is observed during the hydroxycarbonylation of isobutylene with carbon monoxide and glycerin.

Thus, the feasibility of the synthesis of isovaleric acid esters with aliphatic polyols by means of alkoxycarbonylation of isobutylene in the presence of the catalytic system $\mathrm{Pd}(\mathrm{Acac})_{2}-\mathrm{PPh}_{3}-\mathrm{TsOH}$ was established. The reaction proceeds regioselectively at the terminal atom of isobutylene. Isovaleric acid monoglyceride is formed only in the form of the $\alpha$-isomer.

The proposed methods are highly economical and may be used for commercial production of the mentioned above biological active esters of the isovaleric acid. Optimal technological parameters for carrying out the processes were tested at the pilot plant. Technologically, organization of the productions being proposed does not present any great difficulties. Standard equipment may be used. It should be noted that all the proposed productions are based on the similar technology using one and the same equipment.

\section{References}

1. Colquhoun HM (1984) New Pathways for Organic Synthesis: Practical Applications of Transition Metals. Plenum Press New York USA

2. Petrov ES (1988) Palladium Phosphine Complexes in Catalysis of the Olefin Carbonylation Reaction. J Phys Chem 10: 2858-2868 (in Russ).

3. Suerbaev KA, Shalmagambetov KM, Zhubanov KA (2000) Syntheses Based on Monocarbon Molecules: III. Hydroethoxycarbonylation of 2-Methylpropene in the Presence of Palladium Phosphine Complexes at a Low Pressure of Carbon Monoxide. Russian Journal of General Chemistry 70: 1924-1926.

4. Suerbaev KA, Shalmagambetov KM, Zhubanov KA (2000) Syntheses Based on Monocarbon Molecules: IV. Catalytic Regioselective Hydroalkoxycarbonylation of Olefins with Carbon Monoxide and Alcohols in the Presence of the System $\mathrm{PdCl} 2-\mathrm{PPh} 3-\mathrm{p}-\mathrm{TsOH}$ Perfumes from Esters. Russian Journal of General Chemistry 70: 1927-1928.

5. Liu J, Heaton BT, Iggo JA, Whyman R, Bickley JF, et al. (2006) The mechanism of the hydroalkoxycarbonylation of ethene and alkene-CO copolymerization catalyzed by $\mathrm{Pd}(\mathrm{II})$-diphosphine cations. Chemistry 12: 4417-4430.

6. Shulov LM, Kheifets LA (1990) Perfumes and Intermediate Products of Perfumes and Cosmetics Manufacture. Agropromizdat Moscow.

7. Dzhemilev UM, Popad'ko NR, Kozlova EV (1999) Metal Complex Catalysis in Organic Synthesis: Alicyclic Compounds. Khimiya Moscow.

8. Suerbaev KA, Chepaikin EG, Zhaksylykova GZ (2012) Hydromenthoxycarbonylation of Isobutylene in the Presence of Tetrakis (triphenylphosphin)palladium-Based Catalyst Systems. Petrol Chem 52: 422425.

9. Suerbaev KA, Chepaikin EG, Appazov NO, Dzhiembaev BZ (2012) Hydroalkoxycarbonylation of isobutylene with polyhydric alcohols in the presence of catalytic systems based on palladium compounds and tertiary phosphines. Petrol Chem 52: 189-193. 